\title{
PENGARUH ANNEALING TERHADAP SIFAT FISIS DAN MEKANIS PAHAT HSS DENGAN UNSUR PADUAN UTAMA CROM
}

\author{
Bibit Sugito \\ Dosen Jurusan Teknik Mesin Universitas Muhammadiyah Surakarta \\ J1. A.Yani Tromol Pos I Pabelan, Kartosura \\ email : bibit@ums.ac.id
}

\begin{abstract}
ABSTRAKSI
Penelitian ini bertujuan untuk mengamati dan mencocokkan fase yang ada pada pahat HSS dengan standard pengujian yang ada setelah bahan mengalami annealing.

Pelaksanaanya dilakukan dengan memanaskan spesimen terlebih dahulu dengan proses annealing, baru kemudian dilakukan pengujian yang meliputi bahan yang diannealing maupun tidak terhadap unsure kimia, kekerasan dan struktur mikro yang terjadi

Dari hasil pengujian dan pengamatan didapatkan hasil dan kesimpulan sebagai berikut bahwa, paduan utamanya lebih dari $7 \%$ ini berarti termasuk baja paduan tinggi. ( Baja chrom )Pada bagian dalam sebelum di Annealing kekerasan ratarata 1059,86 kg/mm ${ }^{2}$. Sedangkan pada bagian dalam setelah di Annealing kekerasan rata-rata adalah 300,46 kg/ $\mathrm{mm}^{2}$, bahan sebelum di Annealing terdapat lima fase, yaitu fase martensit, sementite, FeCr, Co. Sedangkan sesudah di Annealing terdapat empat fase yaitu fase perlite, sementite, $\mathrm{FeCr}$, Co dan Mo.
\end{abstract}

Kata-kata kunci: Unsur kimia, Vickers, Annealing, fase, Baja chrom

\section{PENDAHULUAN}

Bahan logam pada jenis besi, baja adalah material yang sering digunakan membuat paduan logam lain untuk mendapatkan sifat bahan yang diinginkan. Pada tahun 1898 ditemukan jenis baja paduan tinggi dengan unsur paduan krom (Cr) dan tungsten / wolffram (W). Melalui proses penuangan (molten metallurgy) kemudian diikuti pengerolan ataupun penempaan baja ini dibentuk menjadi batang atau silinder. Pada kondisi lunak (annealed) bahan tersebut dapat diproses secara permesinan menjadi berbagai bentuk pahat potong. Setelah proses laku panas dilaksanakan, kekerasan akan cukup tinggi sehingga dapat digunakan pada kecepatan potong yang tinggi (sampai dengan 3 kali kecepatan potong untuk pahat CTS yang dikenal pada saat itu sekitar $10 \mathrm{~m} / \mathrm{menit}$, sehingga dinamakan dengan "Baja Kecepatan Tinggi"; HSS, (High Speed Steel). Apabila telah aus HSS dapat diasah sehingga mata potongnya tajam kembali. Karena sifat keuletan yang relatif baik maka sampai saat ini berbagai jenis HSS masih tetap digunakan.

Penelitian ini dilakukan dengan tujuan untuk mengetahui sifat fisis dan mekanis pahat jenis HSS dari bahan baja paduan tinggi dengan perlakuan panas (heat treatment.

\section{TINJAUAN PUSTAKA}

F.H.Lege (1995) penelitian pada Carbon Tool Steel yang dipanaskan 
dengan austemper menyimpulkan penahanan waktu yang ideal untuk carbon tool steel pada transformasi isotermal $\left(350^{\circ} \mathrm{C}\right.$ dan $\left.400^{\circ} \mathrm{C}\right)$ untuk mendapatkan $100 \%$ bainit adalah antara 5 - 10 detik, struktur mikro yang sama akan terlihat pada hasil uji struktur menunjukkan transformasi sudah melewati garis Ts ( transformasi finish) dengan transformasi bainit $100 \%$, kekerasan tergantung pada prosentase bainit dan perlit. Dimana kekerasannya lebih tinggi dari spesimen awal dan lebih lunak dari kekerasan bainit.

\section{METODE PENELITIAN}

\section{Rancangan penelitian}

Jalannya penelitian dapat dilihat pada gambar 1.

\section{Lokasi Penelitian}

Penelitian dilakukan di laboratorium Metalurgi Jurusan Teknik Mesin UMS

\section{Uji Komposisi Kimia}

Pada pengujian komposisi kimia dilakukan dengan Spectrum Komposisi Kimia Universal sebanyak 4 titik fokus tembak dengan gas argon. Dari empat titik fokus tembak tersebut didapatkan hasil pengujian berupa kandungan komposisi kimia dengan unsur utama $\mathrm{Fe}$ dan unsur paduan utama Chrom lebih rincinya dapat dilihat pada tabel 1 .

\section{Uji Kekerasan}

Pengujian dilakukan dengan alat uji kekerasan Vikers dengan pembebanan 500 gf dan diameter bola baja $2,5 \mathrm{~mm}$, dilakukan sebanyak 3 kali pada titik yang berbeda dari tepi ke tengah dengan waktu pembebanan 5 detik. Uji kekerasan dilakukan pada sisi tajam atau bagian pemotong pahat dan bagian dalam pahat HSS.

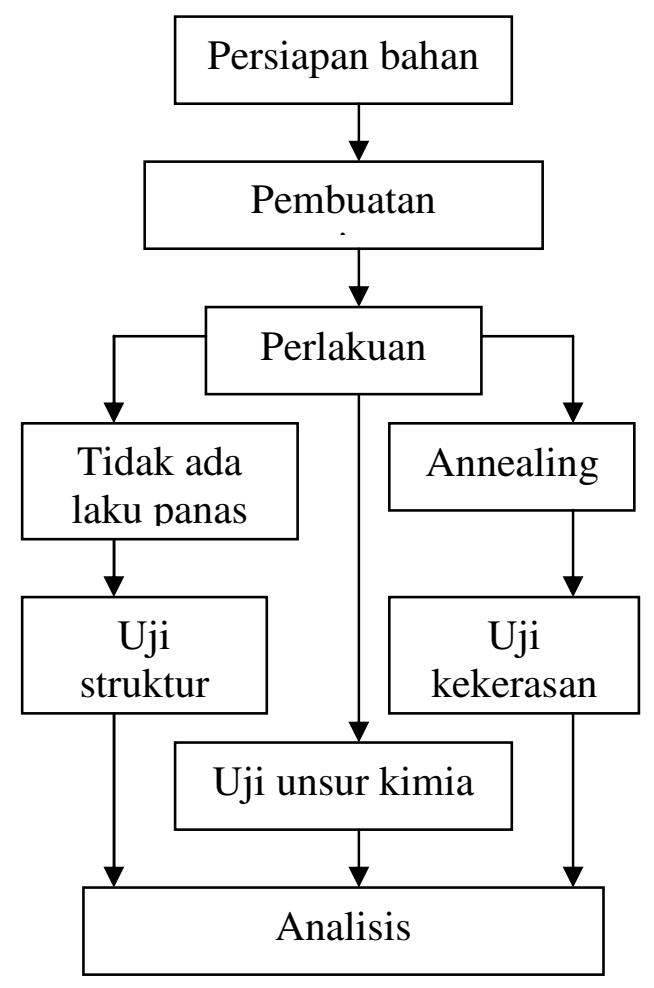

Gambar 1. Rancangan penelitian 
HASIL DAN PEMBAHASAN

Hasil Uji Komposisi Kimia

Pada pengujian komposisi kimia, dari empat titik fokus tembak didapatkan hasil pengujian berupa kandungan komposisi kimia dengan unsur utama Fe dan unsur paduan utama Chrom lebih rincinya dapat dilihat pada tabel 1.

Tabel 1. Data Hasil Pengujian Komposisi Kimia

\begin{tabular}{ccc}
\hline No. & Unsur \% & Rata-rata \% \\
\hline 1 & $\mathrm{Fe} 2$ & 82,11 \\
2 & $\mathrm{C}$ & 1,15 \\
3 & $\mathrm{Si}$ & 1.25 \\
4 & $\mathrm{Mn}$ & 0,556 \\
5 & $\mathrm{P}$ & 0,047 \\
6 & $\mathrm{~S}$ & 0,000 \\
7 & $\mathrm{Cr}$ & 6,22 \\
8 & $\mathrm{Mo}$ & 2,83 \\
9 & $\mathrm{Ni}$ & 0,364 \\
10 & $\mathrm{Al}$ & 0,031 \\
11 & $\mathrm{~B}$ & 0,0022 \\
12 & $\mathrm{Co}$ & 2,58 \\
13 & $\mathrm{Cu}$ & 0,141 \\
14 & $\mathrm{Nb}$ & 0,047 \\
15 & $\mathrm{~Pb}$ & 0,0234 \\
16 & $\mathrm{Sn}$ & 0,036 \\
17 & $\mathrm{Ti}$ & 0,058 \\
18 & $\mathrm{~V}$ & 1,87 \\
19 & $\mathrm{~W}$ & 0,490 \\
\hline
\end{tabular}

\section{Hasil Uji Kekerasan}

Tabel 2. Hasil uji kekerasan sisi tajam pahat HSS sebelum di Annealing

\begin{tabular}{cccccc}
\hline No & Jarak $(\mathbf{m m})$ & $\mathbf{D 1}(\boldsymbol{\mu m})$ & D2 $(\boldsymbol{\mu m})$ & D $(\boldsymbol{\mu m})$ & $(\mathbf{H V N})$ \\
\hline 1 & 0.2 & 29.2 & 27.6 & 28.4 & 1149.6 \\
2 & 0.7 & 30.2 & 30.0 & 30.1 & 1023.4 \\
3 & 1.5 & 30.3 & 30.4 & 30.4 & 1006.6 \\
& & Rata-rata & & & 1059.86 \\
\hline
\end{tabular}

Tabel 3. Hasil uji kekerasan pada bagian dalam pahat HSS sebelum di Annealing

\begin{tabular}{cccccc}
\hline No & Posisi & D1 $(\boldsymbol{\mu m})$ & D2 $(\boldsymbol{\mu m})$ & D $(\boldsymbol{\mu m})$ & $(\mathbf{H V N})$ \\
\hline 1 & Acak & 30.2 & 30.4 & 30.3 & 1009.9 \\
2 & Acak & 30.5 & 30.4 & 30.5 & 1000.0 \\
3 & Acak & 30.3 & 30.6 & 30.5 & 1000.0 \\
& & Rata-rata & & & 1003.3 \\
\hline
\end{tabular}


Tabel 4. Hasil uji kekerasan pada sisi tajam atau bagian pemotong pahat HSS setelah di

\begin{tabular}{rccccc}
\multicolumn{5}{c}{ Annealing pada $950^{\circ} \mathrm{C}$} \\
\hline No & Jarak $(\mathbf{m m})$ & $\mathbf{D 1}(\boldsymbol{\mu m})$ & $\mathbf{D 2}(\boldsymbol{\mu m})$ & $\mathbf{D}(\boldsymbol{\mu m})$ & $(\mathbf{H V N})$ \\
\hline 1 & 0.2 & 60.2 & 60.3 & 60.25 & 255.4 \\
2 & 0.7 & 54.3 & 54.2 & 54.25 & 315.9 \\
3 & 1.5 & 53.4 & 52.6 & 53.00 & 330.1 \\
& & Rata-rata & & & 300.46 \\
\hline
\end{tabular}

Tabel 5. Data hasil uji kekerasan pada sisi dalam pahat HSS setelah di Annealing pada suhu

\begin{tabular}{cccccc}
\multicolumn{7}{c}{$950^{\circ} \mathrm{C}$} \\
\hline No & Posisi titik & D1 $(\boldsymbol{\mu m})$ & D2 $(\boldsymbol{\mu m})$ & D $(\boldsymbol{\mu m})$ & $(\mathbf{H V N})$ \\
\hline 1 & Acak & 60.4 & 60.2 & 60.30 & 255.0 \\
2 & Acak & 55.6 & 56.3 & 55.95 & 296.2 \\
3 & Acak & 54.2 & 54.8 & 54.50 & 312.2 \\
& & Rata-rata & & & 287.8 \\
\hline
\end{tabular}

\section{Hasil Uji Struktur Mikro}

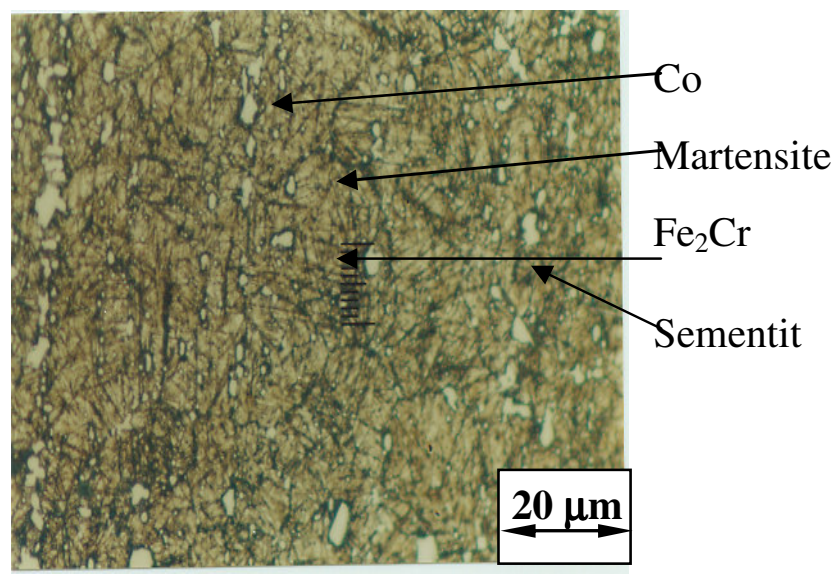

Gambar 2. Perbesaran 500x sebelum Annealing

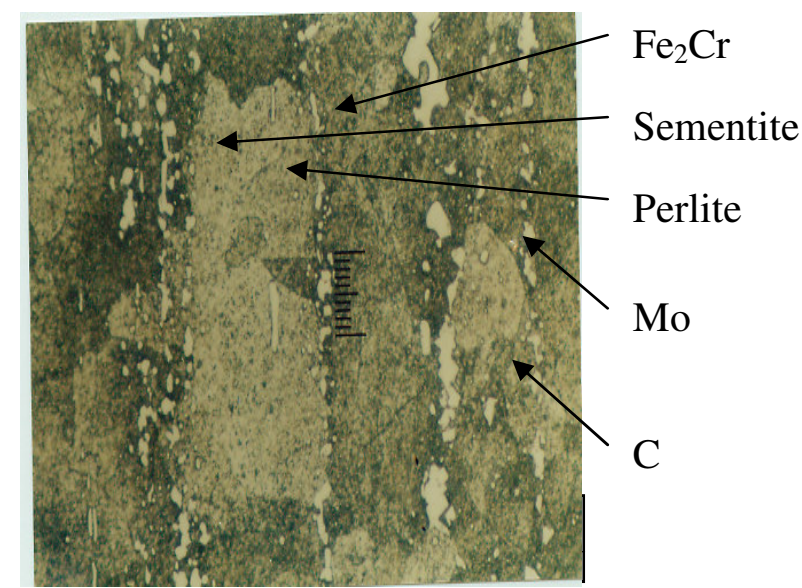

Gambar 3. Foto Struktur Mikro Perbesaran 500x pada pahat HSS sesudah Annealing pada suhu $950^{\circ}$. 


\section{Pembahasan}

Dari data hasil pengujian yang dilakukan meliputi komposisi kimia, kekerasan, struktur mikro adalah sebagai berikut. Prosentase dari unsur karbonnya yang mencapai lebih dari $0,8 \%$ yaitu unsur karbonnya $1.15 \%$ termasuk unsur baja karbon tinggi dan bila di lihat dari unsur paduannya melebihi dari $7 \%$, ini berarti termasuk baja paduan tinggi.

Analisa unsur paduan yang dilakukan pada penelitian ini meliputi $\mathrm{W}, \mathrm{Cr}, \mathrm{V}, \mathrm{Mo}, \mathrm{Co}$. Berikut pengaruh beberapa paduan pada unsur besi $(\mathrm{Fe})$ dan karbon (C) yang memberikan efek baik dan buruk :Dengan menambahkan $0,4 \%$ sampai $0,9 \%$ Mo dalam HSS dalam paduan utama W (WHSS) dapat dihasilkan HSS yang mampu dikeraskan diudara (airhardening properties). Mo-HSS lebih liat sehingga mampu menahan beban kejut. Kejelekannya adalah lebih sensitif terhadap overheating.

Analisa unsur paduan yang dilakukan pada penelitian ini meliputi $\mathrm{W}, \mathrm{Cr}, \mathrm{V}$, Mo, Co. Berikut pengaruh beberapa paduan pada unsur besi (Fe) dan karbon (C) yang memberikan efek baik dan buruk :Tungsten atau wolfram dapat membentuk karbida yaitu paduan yang sangat keras $\left(\mathrm{Fe}_{4} \mathrm{~W}_{2} \mathrm{C}\right)$ yang menyebabkan kenaikan temperatur untuk proses hardening dan tempering. Chromium (Cr) dapat menaikkan hardenability dan hot hardeness. Chrom merupakan elemen pembentuk karbida, akan tetapi $\mathrm{Cr}$ menaikan sensitifitas terhadap overheating. Sedangkan Vanadium (V) akan menurunkan sensitivitas terhadap overheating serta menghaluskan besar butir. Vanadium juga merupakan elemen pembentuk karbida. Molybdenum (Mo) Dengan menambahkan $0,4 \%$ sampai $0,9 \%$ dalam HSS dalam paduan utama W (WHSS) dapat dihasilkan HSS yang mampu dikeraskan diudara (airhardening properties). Mo-HSS lebih liat sehingga mampu menahan beban kejut. Kejelekannya adalah lebih sensitif terhadap overheating.Cobalt (Co)yang ditambahkan dalam HSS adalah untuk menaikan hot hardness dan ketahanan keausan.

\section{KESIMPULAN}

Berdasarkan uji spectrum, bahwa prosentase dari unsur paduannya yang lebih dari $7 \%$ tergolong baja paduan tinggi.

Berdasarkan uji kekerasan, bahwa spesimen setelah perlakuan panas harga kekerasannya menurun. Pada pahat HSS pada sisi yang tajam sebelum di Annealing mempunyai kekerasan rata-rata 1059,86 $\mathrm{kg} / \mathrm{mm}^{2}$, dan pada bagian dalam pahat HSS mempunyai kekerasan rata-rata 1000,3 $\mathrm{kg} / \mathrm{mm}^{2}$. Sedangkan pada pahat HSS pada sisi yang tajam setelah di Annealing mempunyai kekerasan rata-rata adalah $300,46 \mathrm{~kg} / \mathrm{mm}^{2}$, dan pada bagian dalam pahat HSS setelah di Annealing mempunyai kekerasan rata-rata adalah $287,8 \mathrm{~kg} / \mathrm{mm}^{2}$.

Berdasarkan uji struktur mikro, dari hasil pemotretan dengan perbesaran 500x maka didapatkan bahwa pada pahat yaitu fase martensit, sementite, $\mathrm{FeCr}$, Co. Sedangkan pada pahat HSS sesudah annealing terdapat empat fase yaitu fase perlite, sementit, $\mathrm{Fe} \mathrm{Cr}$, Co dan Mo. 


\section{DAFTAR PUSTAKA}

Barret, S.C. 1952, Structure of Metal. $2^{\text {nd }}$ Edition. Mc.Graw Hill Book Company. New York.

Merica,P.D, Waltenberg, R.G. dan Sccot, H.1920, Trans ASME, Volume 64, Mc.Graw Hill Book Company .New York.

Surdia.T,. Saito, S, 2000, Pengetahuan Bahan Teknik., Cetakan ke-5 Pradnya Paramita Jakarta.

Van Vlack, LH., 2004, Elemen - Elemen Ilmu dan Rekayasa Material, PT.Pradnya Paramita, Jakarta.

Van Vliet, GLJ., Borth, W,1984, Bahan-bahan, Edisi Ke-1.PT.Erlangga, Jakarta.

F.H.Lege, 1995, Penelitian tentang Carbon tool steel yang dipanaskan, Tugas akhir S1, UMM. Malang

1984, ASM Hand Book, Metallography and Microstructure. Volume 9, American Society for Metals. Ohio. 